\title{
Life Science
}

\section{http://journal.unnes.ac.id/sju/index.php/LifeSci}

\section{Keanekaragaman Jenis Lichen di Kota Semarang}

\author{
Husna Mafaza ${ }^{\bowtie}$, Murningsih, dan Jumari
}

Laboratorium Ekologi dan Biosistematika, Departemen Biologi, Fakultas Sains dan Matematika, Universitas Diponegoro, Semarang

\section{Info Artikel}

Diterima: 1 Maret 2019

Disetujui: 30 Maret 2019

Dipublikasikan: 25 April 2019

\section{Keywords:}

bioindicator, diversity, lichen,

shade tree, talus type,

bioindikator,

keanekaragaman, lichen,

pohon peneduh, tipe talus.

\begin{abstract}
Lichen is often used as a bioindicator of air pollution in an area because it is sensitive to pollution. The morphological structure of lichen that does not have a cuticle, stomata, and absorptive organ, forces lichens to survive under the stress of pollutants found in the air. The sensitivity of lichen to air pollution can be seen through changes in diversity. The purpose of this study was to examine the diversity of species of lichens, to assess the environmental conditions and shade trees as habitat for lichens in the city of Semarang. The research was conducted from October to November 2017 using the purposive random sampling method. Sampling was conducted at three research stations, namely: Mangkang Terminal, Simpang Lima Area, and Undalang Tembalang Campus. Based on the results of research at the three observation stations, 18 lichen species were obtained, 13 species were identified and 5 species were not identified. Lichen obtained as many as 8 families, namely Arthoniaceae, Caloplacaceae, Physciaceae, Graphidaceae, Lecanoraceae, Lecidellaceae, Leprariaceae and Parmeliaceae. These types of lichen belong to the talus group foliose and crustose. The shade tree that is most overgrown with lichens is mahogany (Swietenia mahagoni). The Shannon-Wiener diversity index values in the three research stations were: Terminal Mangkang (1.88), Simpang Lima Region (2.95), and Undip Tembalang Campus (3.71). The highest number of species and number of individuals is at the Undip Tembalang Campus, with a total of 17 species and 295 individuals lichen. Dirinaria spp. is the most found species in all three research stations.
\end{abstract}

\begin{abstract}
Abstrak
Lichen sering dipakai sebagai bioindikator pencemaran udara di suatu daerah karena sifatnya yang sensitif terhadap polusi. Struktur morfologi lichen yang tidak memiliki lapisan kutikula, stomata, dan organ absorptif, memaksa lichen untuk bertahan hidup di bawah cekaman polutan yang terdapat di udara. Sensitivitas lichen terhadap pencemaran udara dapat dilihat melalui perubahan keanekaragamannya. Tujuan dari penelitian ini adalah untuk mengkaji keanekaragaman jenis lichen, mengkaji kondisi lingkungan dan pohon peneduh sebagai habitat lichen di Kota Semarang. Penelitian dilaksanakan pada bulan Oktober hingga November 2017 menggunakan metode purposive random sampling. Sampling dilakukan di tiga stasiun penelitian, yakni: Terminal Mangkang, Kawasan Simpang Lima, dan Kampus Undip Tembalang. Berdasarkan hasil penelitian di ketiga stasiun pengamatan, diperoleh 18 spesies lichen, 13 spesies berhasil diidentifikasi dan 5 spesies belum teridentifikasi. Lichen yang diperoleh sebanyak 8 famili yakni Arthoniaceae, Caloplacaceae, Physciaceae, Graphidaceae, Lecanoraceae, Lecidellaceae, Leprariaceae dan Parmeliaceae. Jenis lichen tersebut termasuk dalam kelompok talus foliose dan crustose. Pohon peneduh yang paling banyak ditumbuhi lichen adalah mahoni (Swietenia mahagoni). Nilai indeks keanekaragaman Shannon-Wiener di ketiga stasiun penelitian yaitu: Terminal Mangkang $(1,88)$, Kawasan Simpang Lima (2,95), dan Kampus Undip Tembalang (3,71). Jumlah jenis dan jumlah individu tertinggi terdapat di Kampus Undip Tembalang, dengan total 17 spesies dan 295 individu lichen. Dirinaria spp. merupakan spesies yang paling banyak ditemukan di ketiga stasiun penelitian.
\end{abstract}




\section{PENDAHULUAN}

Lichen merupakan simbiosis antara fungi (mikobiont) dari kelompok Ascomycetes dan Basidiomycetes, dengan alga (fikobiont) dari kelompok Cyanobacteria atau Chlorophyceae (Supriati \& Satriawan, 2013). Lichen dapat digunakan sebagai bioindikator udara. Hal ini disebabkan lichen sangat sensitif terhadap pencemaran udara, memiliki sebaran geografis yang luas, keberadaannya melimpah dan memiliki bentuk morfologi yang relatif tetap dalam jangka waktu yang lama. Struktur morfologi lichen yang tidak memiliki lapisan kutikula, stomata, dan organ absorptif, memaksa lichen untuk bertahan hidup di bawah cekaman polutan yang terdapat di udara (Panjaitan et al., 2012).

Lichen mempunyai beragam ukuran, warna dan bentuk (Lukmana, 2012). Corticolous lichens merupakan jenis lichen yang ditemukan hidup sebagai epifit pada substrat kulit batang. Keberadaan jenis lichen ini sangat tergantung pada pohon inangnya karena beberapa jenis lichen memilih jenis pohon tertentu sebagai inang (Susilawati, 2013). Maka perlu untuk mengetahui jenis pohon apa saja yang dapat menjadi substrat dan mendukung kehidupan lichen.

Semarang menempati urutan ketiga tingkat pencemaran udara tertinggi di Indonesia setelah Jakarta dan Bandung. Terminal Mangkang merupakan salah satu lokasi yang memiliki tingkat pencemaran udara paling tinggi karena berfungsi sebagai pusat kegiatan transportasi (Mahawati, 2011). Sedangkan kawasan Industri Mangkang merupakan salah satu kawasan industri terbesar di Kota Semarang (Kartika, 2011). Kemudian untuk pusat kegiatan di kota Semarang terdapat di kawasan Simpang Lima. Kawasan kampus Universitas Diponegoro (Undip) Tembalang merupakan kawasan yang banyak ditemukan pohon yang teduh sebagai habitat dari lichen (Murningsih, 2016).

Lichen merupakan salah satu anggota dari tumbuhan tingkat rendah yang belum mendapatkan perhatian maksimal (Lukmana, 2012). Hingga saat ini belum ada penelitian terhadap jenis-jenis lichen di Kota Semarang. Maka dari itu, Kota Semarang dapat dijadikan sebagai lokasi penelitian mengenai keanekaragaman jenis lichen, khususnya pada tegakan pohon pada jalur hijau. Tujuan dari penelitian ini adalah untuk mengkaji keanekaragaman jenis lichen, mengkaji kondisi lingkungan dan pohon peneduh sebagai habitat lichen di Kota Semarang.

\section{METODE}

Penelitian ini berlangsung sejak bulan Oktober hingga November 2017. Stasiun yang dipilih dalam pengambilan sampel lichen diambil secara purposive atau sengaja, dengan mempertimbangkan stasiun tersebut dianggap mewakili komunitas lichen (Pratiwi, 2006). Stasiun tersebut yaitu; Terminal Mangkang, Simpang Lima dan Kampus Undip Tembalang. Sampling dilakukan pada vegetasi pohon peneduh di jalan raya sebagai tempat hidup lichen.

Untuk masing-masing stasiun diambil 4 plot sampling. Plot sampling pada Terminal Mangkang yaitu; area di dalam terminal, sepanjang jalan depan terminal, jalan di sisi barat terminal dan jalan di sisi timur terminal. Plot sampling pada Simpang Lima yaitu; alun-alun Simpang Lima, Jalan Gadjahmada, Jalan Pahlawan dan Jalan Pandanaran. Plot sampling pada kawasan Kampus Undip Tembalang yaitu; 
jalan depan Fakultas Peternakan dan Pertanian, jalan depan Fakultas Teknik, jalan antara Fakultas Ekonomika dan Bisnis dengan Fakultas Sains dan Matematika, serta jalan depan Biologi Tanaman Obat. Pengamatan dilakukan dengan jarak maksimal sejauh 100 meter pada plot sampling.

Data faktor abiotik yang diamati terdiri dari suhu, kelembaban dan intensitas cahaya (Nurjanah, 2013). Selanjutnya dilakukan pengamatan terhadap kepadatan lalu lintas, yaitu dengan menghitung ratarata jumlah kendaraan bermotor yang melintas di jalan utama di setiap stasiun pengamatan pada pukul 10.00-11.00 WIB. Data faktor biotik yang diamati adalah jenis-jenis pohon peneduh sebagai substrat bagi lichen. Pengambilan sampel lichen di setiap plot sampling dilakukan pada lima jenis pohon peneduh yang berbeda atau lima pohon sesuai dengan ditemukannya lichen.

Pengambilan sampel lichen di setiap pohon dilakukan pada permukaan kulit batang pohon yang menghadap jalan raya dengan ketinggian $50 \mathrm{~cm}$ sampai $150 \mathrm{~cm}$ di atas permukaan tanah (Marcelli, 1992 dalam Asih, 2013). Luas pengamatan lichen dilakukan dengan menggunakan bingkai kuadran plastik transparan berukuran 20x20 cm (Nursal, 2005 dalam Hadiyati, 2013). Langkah setelah pemasangan bingkai kuadran plastik di batang pohon, yaitu dilakukan pencatatan jenis lichen yang berada di dalam kuadran. Lichen kemudian didokumentasikan dengan kamera agar mempermudah identifikasi. Sampel lichen diambil dari setiap jenisnya dengan cara mengerik dari kulit kayu menggunakan pisau, kemudian dilakukan identifikasi jenis lichen di Laboratorium Ekologi dan Biosistematika Universitas Diponegoro. Sampel lichen disimpan dalam amplop, kemudian diberi label/keterangan (Hutajulu, 2014).

\section{HASIL DAN PEMBAHASAN}

\section{Keanekaragaman Lichen}

Keanekaragaman lichen dapat diambil sebagai perkiraan kualitas udara, semakin tinggi nilainya menunjukan lokasi lingkungan yang baik, begitupun sebaliknya (Asta, 2002 dalam Hardianto, 2015). Kampus Undip Tembalang memiliki nilai indeks keanekaragaman tertinggi karena faktor lingkungan yang mendukung pertumbuhan lichen secara optimal (Tabel 1).

Tabel 1. Nilai Indeks Keanekaragaman Lichen pada Ketiga Stasiun Pengamatan di Kota Semarang

\begin{tabular}{lc}
\hline \multicolumn{1}{c}{ Stasiun } & Nilai keanekaragaman jenis (H') \\
\hline Terminal Mangkang & 1,88 \\
Simpang Lima & 2,95 \\
Kampus Undip Tembalang & 3,71 \\
\hline
\end{tabular}

Nilai indeks keanekaragaman jenis lichen pada Terminal Mangkang dan Simpang Lima termasuk dalam kriteria indeks $1<\mathrm{H}^{\prime}<3$ yang menunjukkan keanekaragaman melimpah dan ekosistem yang cukup stabil. Sedangkan nilai indeks keanekaragaman jenis pada Kampus Undip Tembalang termasuk dalam kriteria indeks H'>3 yang menunjukkan keanekaragaman sangat melimpah dengan ekosistem yang sangat stabil. Kehadiran lichen dipengaruhi oleh keadaan lingkunganya dan relatif lebih banyak ditemukan pada lokasi yang tidak tercemar (Danes 2013 dalam Hutajulu, 2014). 
Berdasarkan hasil penelitian di ketiga stasiun pengamatan, terdapat 18 spesies lichen yang ditemukan, 13 spesies yang berhasil teridentifikasi dan 5 spesies yang belum teridentifikasi. Komposisi jenis lichen di Kampus Undip Tembalang memiliki jumlah spesies paling banyak daripada kedua stasiun pengamatan lainnya, yaitu ditemukan 17 jenis lichen. Menurut Murningsih (2016), keanekaragaman lichen di kawasan kampus Undip Tembalang didukung oleh faktor lingkungan, termasuk faktor biotik. Faktor biotik terdiri dari jenis tanaman sebagai substrat bagi lichen.

Lichen yang ditemukan di ketiga stasiun pengamatan sebanyak 8 famili. Sebagian besar lichen yang ditemukan termasuk ke dalam famili Parmeliaceae, yakni terdapat 4 spesies yang ditemukan. Menurut Panjaitan (2012), Lichen Parmeliaceae bentuknya seperti lembaran daun, warnanya hijau hingga hijau keabuabuan, talusnya berbentuk seperti daun atau yang dikenal dengan foliose. Famili Parmeliaceae adalah kelompok lichen foliose terbesar yang memiliki bentuk talus spesifik dan mudah dikenali.

Tabel 2. Keanekaragaman Jenis dan Jumlah Individu Lichen pada 3 Stasiun Pengamatan di Kota

\begin{tabular}{|c|c|c|c|c|c|c|}
\hline \multirow[t]{2}{*}{ No. } & \multirow[t]{2}{*}{ Spesies } & \multirow[t]{2}{*}{ Famili } & \multirow[t]{2}{*}{ Tipe Talus } & \multicolumn{3}{|c|}{ Jumlah Individu Jenis Lichen } \\
\hline & & & & Mangkang & $\begin{array}{l}\text { Simpang } \\
\text { Lima }\end{array}$ & Undip \\
\hline 1. & Arthonia radiata & Arthoniaceae & Crustose & - & 2 & - \\
\hline 2. & Arthonia sp. & Arthoniaceae & Crustose & 23 & 18 & 31 \\
\hline 3. & Caloplaca $s p$ & Caloplacaceae & Crustose & - & - & 1 \\
\hline 4. & Dirinaria spp. & Physiaceae & Foliose & 101 & 42 & 68 \\
\hline 5. & Graphis scripta & Graphiceae & Crustose & - & 36 & 45 \\
\hline 6. & Lecanora sp. & Lepanoraceae & Crustose & - & 15 & 84 \\
\hline 7. & Lecidella sp. & Lecidellaceae & Crustose & - & - & 13 \\
\hline 8. & Lepraria incana & Leprariaceae & Crustose & 4 & 24 & 2 \\
\hline 9. & Lepraria sp. & Leprariaceae & Crustose & - & - & 7 \\
\hline 10. & Parmelia caperata & Parmeliaceae & Foliose & - & - & 1 \\
\hline 11. & Parmelia sp. & Parmeliaceae & Foliose & - & - & 10 \\
\hline 12. & Parmelia sulcata & Parmeliaceae & Foliose & - & - & 5 \\
\hline 13. & Parmotrema sp. & Parmeliaceae & Foliase & - & - & 3 \\
\hline 14. & Unidenfied sp.1 & - & Crustose & 7 & - & 5 \\
\hline 15. & Unidenfied sp.2 & - & Crustose & - & - & 1 \\
\hline 16. & Unidenfied sp.3 & - & Crustose & - & 33 & 2 \\
\hline 17. & Unidenfied sp.4 & - & Crustose & - & 2 & 12 \\
\hline 18. & Unidenfied sp.5 & - & Crustose & - & - & 5 \\
\hline
\end{tabular}

Jenis lichen yang ditemukan pada ketiga stasiun penelitian menunjukan bahwa sebanyak $72 \%$ berasal dari tipe talus crustose, sedangkan 28\% berasal dari tipe talus foliose. Menurut Baron (1999) dalam Pratiwi (2006), tipe talus crustose memiliki ciri-ciri bentuk seperti kerak yang melekat pada substratnya. Tipe talus foliose memiliki ciri-ciri talus mudah terkelupas dari substratnya. Jenis-jenis spesies lichen yang dapat dijumpai pada ketiga stasiun pengamatan adalah Dirinaria spp., Arthonia sp., dan Lepraria incana. Menurut Murningsih (2016), jenis-jenis lichen yang ditemukan di semua stasiun berarti mampu beradaptasi dan cocok hidup pada lingkungan tersebut, ini menunjukkan bahwa spesies tersebut mempunyai kisaran toleransi yang cukup luas terhadap faktor lingkungan. Apabila dilihat dari 
jumlah individu, Kampus Undip Tembalang merupakan stasiun dengan jumlah individu terbanyak, yakni terdapat 295 individu lichen.

\section{Kondisi Lingkungan Penelitian}

Pada masing-masing stasiun penelitian di Kota Semarang, dilakukan pengukuran terhadap faktor-faktor lingkungan. Data faktor abiotik berdasarkan hasil pengamatan dari setiap stasiun dapat dilihat pada (Tabel 3).

Tabel 3. Suhu, Kelembaban, dan Intensitas Cahaya

\begin{tabular}{lccc}
\hline \multicolumn{1}{c}{ Stasiun } & Suhu $(\mathbf{} \mathbf{C})$ & Kelembaban (\%) & Intensitas Cahaya (lux) \\
\hline Mangkang & 30 & 72 & 1840 \\
Simpang Lima & 29 & 70 & 1440 \\
Undip & 28 & 88 & 1048 \\
\hline
\end{tabular}

Dari pengukuran kondisi lingkungan, hasilnya mendukung lichen untuk dapat tumbuh optimal, meski untuk kelembaban di Kampus Undip Tembalang masih melebihi ambang batas optimal. Hal tersebut sesuai dengan pendapat Hadiyati et al. (2013) bahwa suhu optimal bagi pertumbuhan lichen adalah $<40^{\circ} \mathrm{C}$. Suhu udara $45^{\circ} \mathrm{C}$ dapat merusak klorofil pada lichen, sehingga aktivitas fotosintesis dapat terganggu. Nilai intensitas cahaya minimal yang diperlukan lichen untuk berfotosintesis secara efektif adalah 1025 lux. Lichen dapat tumbuh dan berfotosintesis pada kondisi habitat yang sangat lembab (85\%). Kelembaban di atas 85\% dapat mengurangi efektivitas fotosintesis lichen sebesar $35-40 \%$.

Saat ini emisi gas buang hasil pembakaran mesin kendaraan bermotor merupakan faktor penyebab polusi yang paling dominan, terutama di kota-kota besar (Winarno, 2014). Data jumlah kendaraan bermotor diperoleh berdasarkan penghitungan kendaraan pada pukul 10.00-11.00 WIB (Tabel 4).

Tabel 4. Jumlah Kendaraan Bermotor

\begin{tabular}{lccc}
\hline \multicolumn{1}{c}{ Stasiun } & Motor & Mobil & Jumlah \\
\hline Mangkang & 1988 & 2173 & 4161 \\
Simpang Lima & 3196 & 2129 & 5325 \\
Undip & 4222 & 579 & 4801 \\
\hline
\end{tabular}

Kendaraan yang melintasi Terminal Mangkang rata-rata sejumlah 4161 kendaraan. Sedangkan di Simpang Lima rata-rata berjumlah 5325 kendaraan. Kemudian di kampus Undip Tembalang ratarata berjumlah 4801 kendaraan. Apabila dilihat dari jumlah kendaraan yang melintas, maka lokasi Simpang Lima adalah yang paling padat kendaraan dan kemungkinan paling besar polusi udaranya, diikuti kampus Undip Tembalang, kemudian Terminal Mangkang.

Selanjutnya faktor biotik yang diamati adalah pohon peneduh yang dapat menjadi habitat tumbuh bagi lichen. Dari hasil pengamatan di ketiga stasiun, terdapat 11 jenis pohon yang terdiri dari 8 famili yang menjadi habitat bagi lichen (Tabel 5). 
Tabel 5. Jenis Pohon Peneduh sebagai Habitat Lichen di Kota Semarang

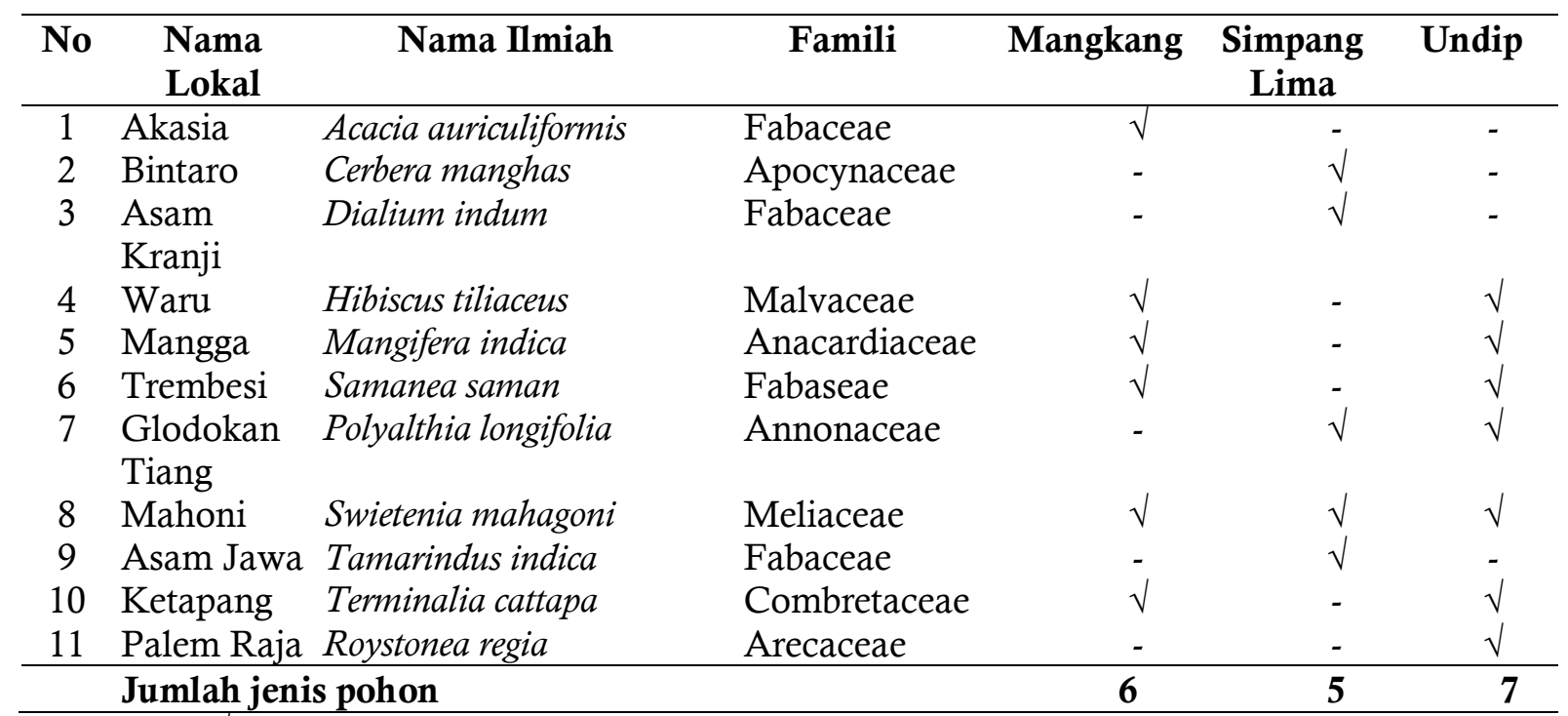

Keterangan: $\sqrt{ }$ : ada, -: tidak ada

Pada penelitian ini, mahoni (Swietenia mahagoni) adalah jenis pohon yang ditemukan di seluruh stasiun pengamatan dan paling banyak ditumbuhi berbagai jenis lichen. Jumlah jenis pohon yang paling banyak adalah di kampus Undip Tembalang, yakni terdapat tujuh jenis pohon yang menjadi tempat hidup lichen.

\section{SIMPULAN}

Berdasarkan hasil penelitian, dapat disimpulkan bahwa jenis-jenis lichen di Kota Semarang diperoleh 18 spesies lichen, 13 spesies berhasil diidentifikasi dan 5 spesies belum teridentifikasi. Terdapat dua tipe talus yang ditemukan, yaitu tipe foliose dan crustose, tipe crustose merupakan tipe talus lichen yang paling banyak ditemukan. Nilai indeks keanekaragaman Shannon-Wiener di ketiga stasiun penelitian yaitu: Terminal Mangkang $(1,88)$ dan Kawasan Simpang Lima $(2,95)$ menunjukkan keanekaragaman melimpah, sedangkan Kampus Undip Tembalang $(3,71)$ menunjukkan keanekaragaman sangat melimpah.

\section{DAFTAR PUSTAKA}

Asih, S.M. (2013). Keanekaragaman jenis lichenes epifit pada hutan kopi dan hutan campuran di Nglimut Gonoharjo Kendal. [Skripsi]. Semarang: Fakultas Sains dan Matematika Universitas Diponegoro.

Hadiyati, M., Setyawati, T.R. \& Mukarlina. (2013). Kandungan sulfur dan klorofil thallus lichen Parmelia $s p$. dan Graphis sp. pada pohon peneduh jalan di Kecamatan Pontianak Utara. Protobiont, 2(1), 1217.

Hutajulu, R.H. (2014). Keanekaragaman jenis lumut kerak yang hidup pada kulit kayu sebagai bioindikator pencemaran udara. [Skripsi]. Bogor: Fakultas Kehutanan Institut Pertanian Bogor.

Hardini, Y. (2010). Keanekaragaman lichen di Denpasar sebagai bioindikator pencemaran udara. Seminar Nasional Biologi Fakultas Biologi UGM. Yogyakarta: UGM Press.

Hardianto, R.I. (2015). Respon lumut kerak pada vegetasi pohon sebagai bioindikator pencemaran udara di Kawasan Industri Jakarta Timur. [Skripsi]. Bogor: Fakultas Kehutanan Institut Pertanian Bogor. 
Kartika, M.P. (2011). Rusunawa buruh di Kawasan Industri Mangkang Semarang. [Tugas Akhir]. Semarang: Universitas Diponegoro.

Lukmana, W. (2012). Keanekaragaman jenis lichenes pada tegakan pohon rasamala (Altingia excelsa) di tahura Bukit Barisan Tongkoh Kab. Karo dan Hutan Aek Nauli Parapat Kab. Simalungun. [Skripsi]. Medan: Universitas Negeri Medan.

Mahawati. (2011). Faktor-faktor risiko paparan $\mathrm{Pb}$ pada polisi lalu lintas di Semarang Barat. Jurnal Visikes, 10(2), 130-137.

Nurjanah, S., Anitasari, Y., Mubaidullah, S. \& Bashri, A. (2013). Keragaman dan kemampuan lichen menyerap air sebagai bioindikator pencemaran udara di Kediri. 10(1). Surakarta: Proceeding Biology Education Conference: Biology, Science, Environmental and Learning.

Maulidiyah. (2011). Isolasi dan penentuan struktur serta uji bioaktivitas senyawa kimia dari ekstrak aseton lichen Usnea blepharea Motyka dan Usnea flexuosa Tayl. [Disertasi]. Depok: Pascasarjana Ilmu Kimia Universitas Indonesia.

Murningsih \& Mafaza, H. (2016). Jenis-jenis lichen di Kampus Undip Semarang. Bioma, 18(1), 20-29.

Panjaitan, D.M., Fitmawati, \& Martina, A. (2012). Keanekaragaman lichen sebagai bioindikator pencemaran udara di Kota Pekanbaru Provinsi Riau, 01, 1-17. Pekanbaru: Fakultas Matematika dan Ilmu Pengetahuan Alam Universitas Riau.

Pratiwi, M.E. (2006). Kajian lumut kerak sebagai bioindikator kualitas udara (studi kasus: Kawasan Industri Pulo Gadung, Arboretum Cibubur, dan Tegakan Mahoni Cikabayan). [Skripsi]. Bogor: Fakultas Kehutanan Institut Pertanian Bogor.

Supriati, R. \& Satriawan, D. (2013). Keragaman jenis lichen di Kota Bengkulu. [Laporan Penelitian Dosen Pemula]. Bengkulu: Universitas Bengkulu.

Susilawati, P.R. (2013). Keanekaragaman corticolous lichen dan preferensi inangnya dengan Erythrina lithosperma Miq., Pinus merkusii Jungh. \& De Vr. dan Engelhardtia spicata Blume di Bukit Bibi, Taman Nasional Gunung Merapi. [Thesis]. Yogyakarta: Universitas Gadjah Mada.

Winarno, J. (2014). Studi emisi gas buang kendaraan bermesin bensin pada berbagai merk kendaraan dan tahun pembuatan. Jurnal Teknik Universitas Janabadra. On line at <http://jurnalteknik.janabadra.ac.id/wp-content/uploads/2015/01/6-Joko-Winarno-April2014.pdf>. 